\title{
Silicon Quantum Dots in a Dielectric Matrix for All-Silicon Tandem Solar Cells
}

\author{
Eun-Chel Cho, ${ }^{1}$ Martin A. Green, ${ }^{1}$ Gavin Conibeer, ${ }^{1}$ Dengyuan Song, ${ }^{1}$ Young-Hyun Cho, ${ }^{1}$ \\ Giuseppe Scardera, ${ }^{1}$ Shujuan Huang, ${ }^{1}$ Sangwook Park, ${ }^{1}$ X. J. Hao, ${ }^{1}$ Yidan Huang, ${ }^{1}$ and Lap Van Dao ${ }^{2}$ \\ ${ }^{1}$ ARC Photovoltaics Centre of Excellence, University of New South Wales, Sydney 2052, NSW, Australia \\ ${ }^{2}$ ARC Centre of Excellence for Coherent X-Ray Science, Swinburne University of Technology, Hawthorn 3122, VIC, Australia
}

Received 1 April 2007; Accepted 26 June 2007

Recommended by Armin G. Aberle

We report work progress on the growth of Si quantum dots in different matrices for future photovoltaic applications. The work reported here seeks to engineer a wide-bandgap silicon-based thin-film material by using quantum confinement in silicon quantum dots and to utilize this in complete thin-film silicon-based tandem cell, without the constraints of lattice matching, but which nonetheless gives an enhanced efficiency through the increased spectral collection efficiency. Coherent-sized quantum dots, dispersed in a matrix of silicon carbide, nitride, or oxide, were fabricated by precipitation of Si-rich material deposited by reactive sputtering or PECVD. Bandgap opening of Si QDs in nitride is more blue-shifted than that of Si QD in oxide, while clear evidence of quantum confinement in Si quantum dots in carbide was hard to obtain, probably due to many surface and defect states. The PL decay shows that the lifetimes vary from 10 to 70 microseconds for diameter of $3.4 \mathrm{~nm}$ dot with increasing detection wavelength.

Copyright ( $) 2007$ Eun-Chel Cho et al. This is an open access article distributed under the Creative Commons Attribution License, which permits unrestricted use, distribution, and reproduction in any medium, provided the original work is properly cited.

\section{INTRODUCTION}

Wafer-based first-generation photovoltaic technologies are presently booming, a situation likely to continue for the next decade. However, second-generation thin-film approaches also appear attractive because of their potential reduction in material costs. Third-generation approaches aim to reduce the manufacturing cost of thin-film second-generation technologies by increasing the efficiency through using multiple energy thresholds, whilst still using abundant and non-toxic materials. The effects of increasing efficiency and lowering the cost of thin-film processes can significantly leverage costs per peak watt $(\mathrm{Wp})$ of generating capacity, perhaps to less than US \$ 0.20/Wp [1].

Figure 1 shows main loss mechanisms in a standard p$\mathrm{n}$ junction solar cell. The most important loss mechanisms in single $\mathrm{p}-\mathrm{n}$ junction solar cells are the nonabsorption of below-bandgap photons (1) in Figure 1) and thermalization of electron-hole pairs generated by absorption of shortwavelength photons, through electron (hole) relaxation to the conduction (valence) band edge (2) in Figure 1). Other losses are junction loss (3) in Figure 1) and contact loss (4) in Figure 1), which can be arbitrarily small in an ideal device. Recombination loss (5) in Figure 1) can be reduced to purely radiative recombination again in an ideal device.
There have been proposed three families of approaches for tackling these first two major loss mechanisms [2]: (a) increasing the number of energy levels; (b) capturing hot carriers before thermalisation; and (c) multiple electron-hole pair generation per high energy photon or generation of one higher energy-carrier pair with more than one low energy photon. An implementation of strategy (a), the tandem cells, is the only technology thus far to have been realized with efficiencies exceeding the Shockley-Queisser limit.

The concept of the tandem solar cell is the use of several solar cells of different bandgaps stacked on top of each other, each absorbing photons of different energies, such that the uppermost cell has the highest bandgap and lets the photon less than its bandgap pass through to lower bandgap cells underneath. Most commonly, these cells are contacted in series. The highest efficiency examples are monolithically grown single-crystal lattice-matched devices based on a GaInP/GaAs/Ge triple-junction structure [3]. Another example in less exotically grown materials is micromorph a$\mathrm{Si} / \mu \mathrm{c}-\mathrm{Si}$ tandem cells [4]. Use of silicon also conveys the very significant advantage of use of an abundant nontoxic material.

A further example which shares these advantages is the use of a silicon quantum dot nanostructure in a matrix of 


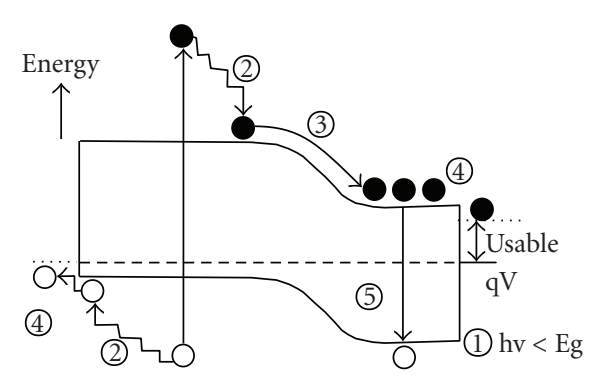

FIGURE 1: Loss mechanism in a standard p-n junction solar cell: (1) nonabsorption of below-bandgap photons, (2) lattice thermalisation loss, (3) junction loss, (4) contact voltage loss, and (5) recombination loss.

silicon oxide, nitride, or carbide to engineer the bandgap of a solar cell material for an "all-Si" tandem cell, whilst also giving a wide range of design flexibility $[5,6]$. In the current paper, we report material properties of silicon nanostructures for all-silicon tandem solar cells and recent progress on silicon nanostructures for all-silicon tandem cell fabrication.

\section{ALL-SILICON QUANTUM DOT TANDEM SOLAR CELL}

Silicon is unique in that it has an almost ideal bandgap not only for a standard single $\mathrm{p}-\mathrm{n}$ junction cell (just a little on the low side of optimal) but also for the lower cell in a twocell or even a three-cell tandem stack (a little on the high side). The efficiency limit for a single silicon cell is $29 \%$, when only radiative and Auger recombination is considered, but this increases to $42.5 \%$ and $47.5 \%$ for two-cell and three-cell stacks, respectively [1]. The optimal bandgap of the top cell to maximize conversion efficiency is $1.7 \sim 1.8 \mathrm{eV}$ for a twocell tandem with an Si bottom cell [7]. The optimal upper and middle bandgaps for a three-cell tandem are $1.5 \mathrm{eV}$ and $2.0 \mathrm{eV}$, respectively. Figure 2 shows the schematic diagram of a silicon-based or "all-silicon" tandem solar cell. The top cell is connected to the bottom cell by an interband tunnel junction, most likely using a defect dominated high interband recombination junction. The material in the interconnection region could also be comprised of quantum dot material, but most likely employing smaller dots than the absorbing regions.

The quantum confinement, achieved by restricting at least one dimension of silicon less to the Bohr radius of the bulk crystalline silicon (around $5 \mathrm{~nm}$ ), causes its effective bandgap to increase. Our early experiments involved carefully thinning the thin silicon layer (50 nm thick) in commercially available silicon-on-insulator (SOI) wafers, resulting in an $\mathrm{SiO}_{2} / \mathrm{Si} / \mathrm{SiO}_{2}$ quantum well [8]. For possibly the first time, clear evidence for a quantum-confined bandgap in an $\mathrm{SiO}_{2} / \mathrm{Si} / \mathrm{SiO}_{2}$ quantum well increase was demonstrated by photoluminescence measurements on such devices, with a lowest energy level (the effective bandgap) of up to $1.7 \mathrm{eV}$ measured for layers about $1 \mathrm{~nm}$ thick. The blue shift of the PL and its rapidly increasing intensity with decreasing Si thickness are indicative of quantum confinement effects. Enhanced PL intensity is directly related to the absorption from the principle of detailed balance [9], which provides an added bonus for solar applications.

The strongest quantum confinement effect is obtained if the silicon is constrained in all three dimensions, as in quantum dots, such that the same increase in effective bandgap can be achieved with a much less stringent size constraint. If these dots are spaced close enough and there is a significant overlap of the wavefunction, carriers can tunnel between them to produce a true quantum dot superlattice. Such a superlattice can then be used as the higher bandgap material in a tandem cell.

Each of the n-type and p-type regions will typically include 20-50 bilayers formed by alternating the growth of a quantum dot (QD) and a dielectric barrier layer. The n-type and p-type regions are typically each in the range of 75$200 \mathrm{~nm}$ thick.

The material requirements for the dielectric layers are ease of thin-film growth and use of abundant nontoxic materials, hence it is most likely to be an oxide, nitride, or carbide of silicon. It is also necessary that carriers from the quantum dot layers have a high probability of tunneling through the dielectric layers. This is achieved by creating each dielectric layer with a thickness in the range of 1.5 to $2.5 \mathrm{~nm}$ for the case of oxide.

The semiconductor material of the quantum dots is preferably silicon or another group IV element such as tin or germanium, or a group IV alloy such as silicon germanium. For a nanostructure to have a high conductivity requires formation of a true superlattice with overlap of the wave function for adjacent quantum dots; which in turn requires either close spacing between QDs or a low barrier height. The wavefunction of an electron confined to a spherical dot penetrates into the surrounding material, decaying approximately as $\exp \left(-r / L_{d}\right) / r$, where $r$ is the distance from the centre of the dot. The decay length $L_{d}$ is determined by the barrier height of the material in which the dot is embedded, which in the present case is either a silicon carbide, nitride, or oxide matrix [10]. In the simplest case, the decay length $\left(L_{d}\right)$ is given by (1):

$$
L_{d}=\frac{1}{\sqrt{2 m^{*}\left(V_{o}-E_{n}\right)}}=\frac{0.1952 \mathrm{~nm}}{\sqrt{m^{*} \cdot \Delta E / m_{o}}} .
$$

The latter expression holds when $\Delta E$, the difference between the conduction band edge of the matrix and the confined energy level, is in eV. $m^{*}$ and $m_{0}$ are the effective mass and electron mass in the matrix material, respectively. $V_{0}$ is the corresponding band offset and $E_{n}$ is the confined energy level in a quantum dot. Without considering the confined energy of QDs, energy difference $\Delta E[5]$ are $3.2 \mathrm{eV}, 1.9 \mathrm{eV}$, and $0.5 \mathrm{eV}$ for the conduction edge of bulk $\mathrm{Si}$ and $\mathrm{SiO}_{2}, \mathrm{Si}_{3} \mathrm{~N}_{4}$, and $\mathrm{SiC}$, respectively. Electrons effective masses of $\mathrm{SiO}_{2}, \mathrm{Si}_{3} \mathrm{~N}_{4}$, and $3 \mathrm{C}-\mathrm{SiC}$ are 0.86 [11], 0.05-0.13 [12], and $0.24 \pm 0.1$ [13], respectively. Following this line of argument, the results suggest that dots in an $\mathrm{SiO}_{2}$ matrix would have to be separated by no more than 1-2 $\mathrm{nm}$ of matrix for a reasonable overlap of the wavefunction and hence of conductivity, while they could be separated by more than $4 \mathrm{~nm}$ of $\mathrm{SiC}$. The same type of calculation allows the effect of fluctuations in spacing and size 


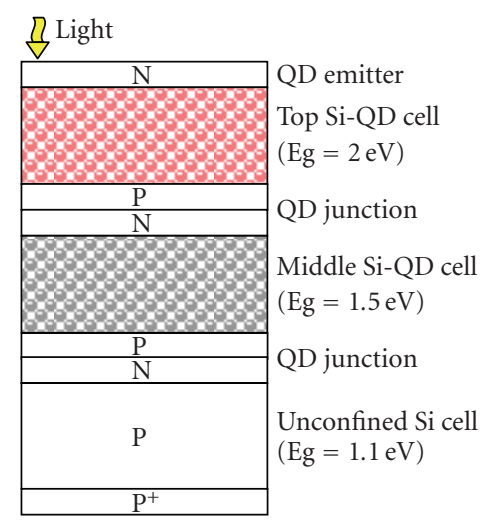

(a)

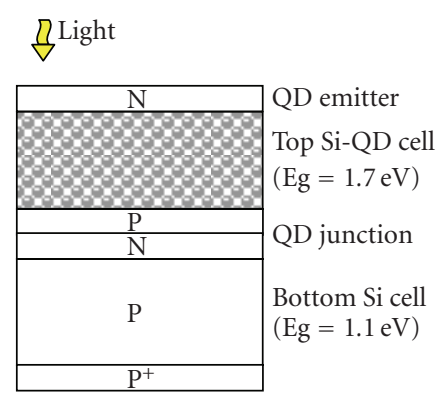

(b)

FIgURE 2: Schematic of (a) three-cell and (b) two-cell tandem solar cell with an Si bottom cell.

of the dots to be investigated. It is found that the calculated Bloch mobilities do not depend strongly on variations in the dot size but do depend strongly on dot spacing uniformity within the QD material [14].

Another requirement for a tandem cell element is the presence of some form of junction for carrier separation. This can either be a grown or a diffused $\mathrm{p}-\mathrm{n}$ junction or a $p-i-n$ junction with the superlattice as i-region. The latter requires careful control of the work functions (and therefore doping) of the $\mathrm{p}$ - and n-regions, but also means that it is not essential for the superlattice itself to be doped.

\section{SILICON QUANTUM DOT SUPERLATTICE}

\subsection{Fabrication of silicon quantum dots}

\subsubsection{Phase precipitation from Si-rich layer}

The effect of quantum confinement obtained by limiting at least one spatial dimension of material has been understood since at least the 1960s and superlattices have been known since 1970. Superlattices were manufacturable with the epitaxial growth techniques available to III-V compound semiconductor technology at that time [15]. Amorphous silicon superlattices of a-Si : $\mathrm{H}$ and $\mathrm{a}-\mathrm{Si}_{1-x} \mathrm{~N}_{x}: \mathrm{H}$ were first reported [16]. Lu et al. reported quantum confinement and light emission of superlattices of silicon and $\mathrm{SiO}_{2}$ fabricated by molecular beam epitaxy (MBE) [17].

Several techniques have been reported for fabricating silicon quantum dots from one of two directions- "bottom up" and "top down." The "bottom up" approach builds up QDs from individual atoms or molecules. This is the basis of most "cluster science" as well as crystal materials synthesis, usually via chemical or vacuum deposition techniques. The methods include gas evaporation [18], high temperature aerosol reaction [19], phase separation of silicon-rich oxide (SRO) by a sputtering [20] and reactive evaporation [21], chemical vapor deposition (CVD) [22], Si implantation into the $\mathrm{SiO}_{2}$ substrate [23], laser ablation [24], and solution synthesis [25].

The "top down" approach generates silicon nanostructures by breaking up bulk materials. This is the basis for techniques such as mechanical milling [26], particle selection formed by electrochemical etching of the silicon substrate (i.e., porous silicon) [27], and precision oxidation of SOI substrates [8]. Approaches explored for producing two-dimensional superlattices in a low cost have not previously proved to be particularly encouraging $[8,28]$. We have demonstrated a bandgap, as measured by PL, of up to $1.7 \mathrm{eV}$, using both an $\mathrm{Si} / \mathrm{SiO}_{2}$ quantum well [8] and an $\mathrm{Si} / \mathrm{SiO}_{2}$ superlattice [28] for layers about $1 \mathrm{~nm}$ thick. The reproducibility of such a thin silicon layer is questionable. The quantum dot superlattice is a promising material because of the additional degree of confinement which gives greater design flexibility than the two-dimensional quantum well structures. The first confined energy level in a $1 \mathrm{~nm}$ wide quantum well will be approximately the same as in a $2 \mathrm{~nm}$ diameter quantum dot [5].

Si ion implantation into an oxide layer can be used to produce Si QDs at an irregular position with a relatively large size distribution. Solution synthesis, mechanical milling, and particle selection from porous silicon can be used to fabricate a volume of Si QDs, but it is difficult to control the size uniformity of distributed QDs or an additional process to select the particle with the same size.

Si QD fabrication by various vacuum deposition techniques is preferable because of the greater potential of integration into conventional devices. Gas phase in situ Si QD growth in an $\mathrm{Si}_{3} \mathrm{~N}_{4}$ matrix film [29] and nanocrystalline precipitations from silicon-rich layers [21] are two examples of fabrication of Si QD systems by means of vacuum deposition techniques. In situ, Si QD growth is an interesting method because a high temperature annealing process is not required. For Si precipitation from an Si-rich layer, high temperature annealing of excess $\mathrm{Si}$ in an inert atmosphere is necessary to form Si nanocrystals with a few $\mathrm{nm}$ diameters, for example, Si QD precipitation in oxide $[21,28,30]$, nitride [31], and carbide [32, 33] (Figure 3(a)). Equation (2) describes this Si precipitation mechanism:

$$
\mathrm{Si}(\mathrm{O}, \mathrm{N}, \mathrm{C})_{x} \longrightarrow\left(\frac{x}{2}\right) \mathrm{Si}\left(\mathrm{O}_{2}, \mathrm{~N}_{4 / 3}, \mathrm{C}\right)+\left(1-\frac{x}{2}\right) \cdot \mathrm{Si}
$$




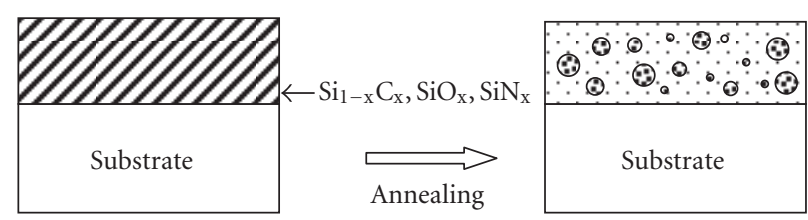

(3) Si QD

(a)

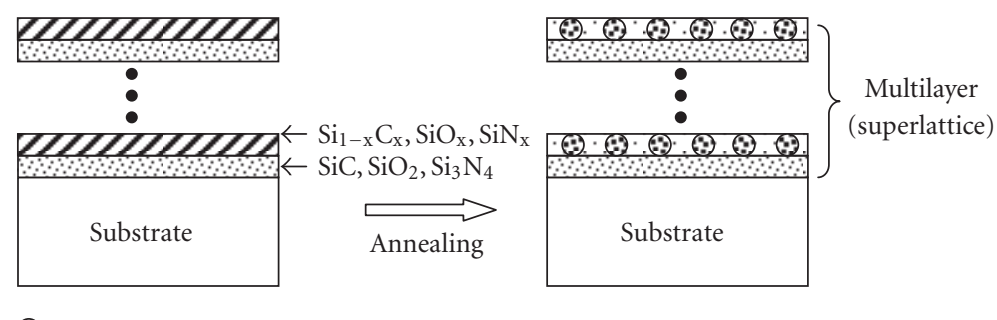

(6) Si QD

(b)

FIGURE 3: Si QDs from phase separation of (a) a single silicon-rich precursor layer and (b) a multilayer structure.

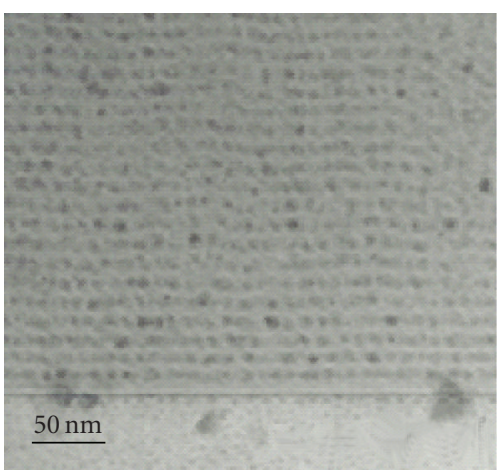

(a)

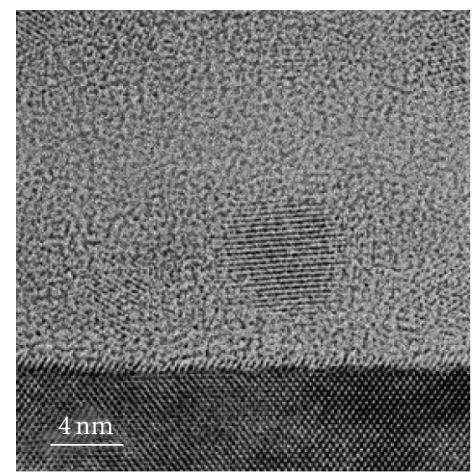

(b)

FIGURE 4: Transmission electron microscopy (TEM) images of Si QDs in $\mathrm{SiO}_{2}$ matrix with (a) low magnification and (b) HRTEM lattice image of Si quantum dots.

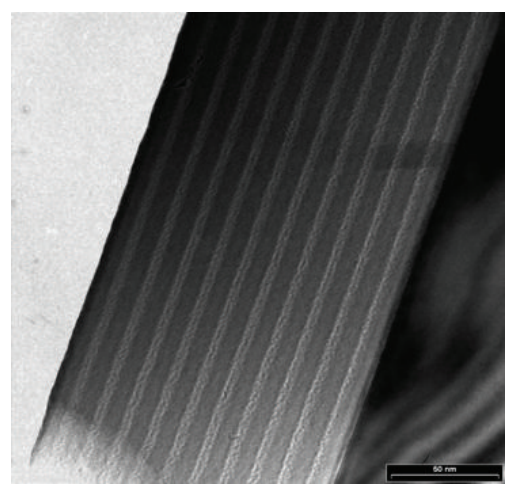

(a)

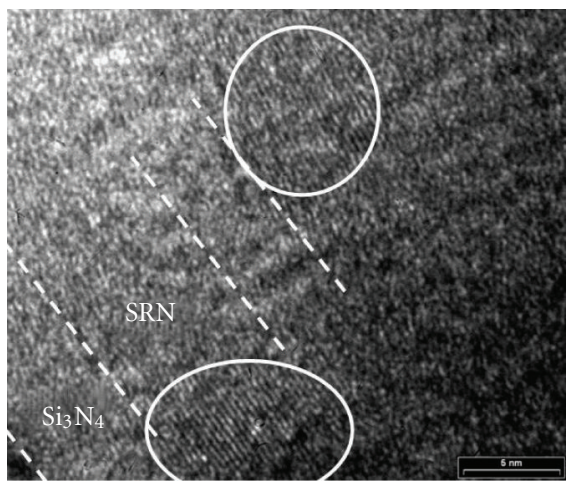

(b)

FIGURE 5: Si QDs dispersed in an $\mathrm{Si}_{3} \mathrm{~N}_{4}$ matrix fabricated by gas phase in situ deposition: (a) low-magnification TEM and (b) high-resolution TEM. 
More accurate size control and a narrow size distribution were achieved by growth of an Si QD multilayer structure, which is fabricated by alternating layers of stoichiometric insulating materials and silicon-rich layers [21, 28] shown in Figure 3(b). Depending on the annealing conditions, silicon precipitates from the silicon-rich layers as approximately spherical QDs of a diameter close to the original layer thickness. Hence controls of the diameter and of one spatial coordinate of the dots are possible. Si QDs in oxide $[6,28]$ and nitride [31] are actively studied materials, but Si QDs in carbide has only recently been attempted $[32,33]$. TEM images in Figure 4 show Si QDs interspersed in the oxide matrix.

\subsubsection{Si quantum dots in a nitride matrix}

The bandgap of $\mathrm{Si}_{3} \mathrm{~N}_{4}$ is significantly lower than that of $\mathrm{SiO}_{2}$. Hence Si QDs in the nitride offer a lower barrier height and much increased carrier tunneling probability between quantum dots. ( $\mathrm{SiC}$ offers a lower barrier still.) For this reason, we have explored transferring the technology of Si QDs in $\mathrm{SiO}_{2}$ to the growth of $\mathrm{Si}$ nanocrystals in silicon nitride by both sputtering and PECVD [31]. For sputtering, growth parameters are very similar to the oxide. In addition, two separate PECVD systems, remote plasma and parallel capacitor plasma, have been used for the growth of Si nanocrystals by depositing alternate Si-rich and stoichiometric nitride layers. Annealing is carried out again at $1100^{\circ} \mathrm{C}$ but with a preannealing at $500^{\circ} \mathrm{C}$ to drive off hydrogen incorporated from the PECVD process. Again, HRTEM images showing even clearer nanocrystals have been obtained. To the best of our knowledge, this is the first Si QDs in multilayered structure in nitride matrix [31].

We have now also extended the layered Si QDs in nitride technology to gas phase in situ deposition. Figure 5 shows in situ Si QD dispersed in a nitride matrix. A stoichiometric $\mathrm{Si}_{3} \mathrm{~N}_{4}$ layer and an in situ Si QD layer are alternately deposited on an Si substrate. This technique allows QDs to form during deposition without a postdeposition annealing. We are actively studying this technique because it is a low temperature process and may be potentially beneficial to doping of Si QDs owing to high equilibrium temperature of the plasma and free of high temperature postannealing described in Figure 3.

\subsubsection{Si QDs in silicon carbide}

$\mathrm{SiC}$ nanocrystals of a few $\mathrm{nm}$ diameters in an $\mathrm{SiO}_{2}$ matrix were produced by silicon and carbon implantation into thermal oxide [34]. However, to our knowledge, little has been reported on the experimental properties of Si QDs embedded in an SiC matrix [32, 33].

A Si-rich amorphous silicon carbide precursor layer can be achieved by control of the sputtering parameters of $\mathrm{Si}$ and carbon containing targets (e.g., pure carbon, silicon carbide, boron carbide, etc.). One way to fabricate Si-rich silicon carbide is cosputtering from silicon and carbon containing targets. Alternatively, small chips of carbon attached to a silicon target can produce an Si-rich silicon carbide precursor layer. A high temperature anneal $\left(800-1200^{\circ} \mathrm{C}\right.$ in an inert gas or in vacuum) of a silicon-rich carbide precursor layer precipitates $\mathrm{Si}$ and/or SiC nanocrystals, depending on its chemical composition as shown in (2).

Raman, TEM, and XRD spectra for a silicon-rich $\mathrm{Si}_{0.75} \mathrm{C}_{0.25}$ precursor layer grown on a quartz substrate with subsequent annealing are shown in Figure 6. There is clear evidence for the formation of nanocrystalline $\mathrm{Si}$ at an anneal temperature greater than $1000^{\circ} \mathrm{C}$. This is shown in the Raman peak at $\sim 508 \mathrm{~cm}^{-1}$ [35]. TEM lattice fringe spacing, consistent with $\{111\}$ Si planes and XRD, peaks at $2 \theta=28.4^{\circ}$ with peak broadening indicating nanocrystal of 3-7 nm (estimated using the Scherrer equation). (It should be noted that the nanocrystal size determined by TEM is, in our experience, always slightly smaller than that determined by XRD.)

Other $\mathrm{Si}$ and $\mathrm{C}$ concentrations were also investigated [33]. As the concentration of $\mathrm{C}$ in $\mathrm{Si}_{1-x} \mathrm{C}_{x}$ is increased to the nearly stoichiometric $\mathrm{Si}_{0.495} \mathrm{C}_{0.505}$, Raman evidence (not shown here), for the stretching vibration modes of $\mathrm{Si}-\mathrm{C}$ and $\mathrm{C}-\mathrm{C}$ bonds, can be easily identified. Intensities of both $\mathrm{TO}$ and LO bands of Raman spectra are increased with increasing annealing temperature, indicating the formation of crystalline $\mathrm{SiC}$ during annealing. In addition, there is a dramatic decrease in the intensity of $\mathrm{Si}-\mathrm{Si}$ vibration modes, indicating the formation of far fewer Si nanocrystals.

HRTEM data (not shown here) shows crystallites with lattice fringes corresponding to $\beta$-SiC $\{111\}$ planes, with a mean size in the range of $3-10 \mathrm{~nm}$. However, in contrast to the spherical Si nanocrystals in the oxide and nitride matrices (see Figures 4 and 5), SiC nanocrystals are irregular with some nanocrystals joined together to form an extended crystal. The difference of nanocrystal shapes from silicon-rich $\mathrm{SiC}$ and near-stoichiometric $\mathrm{SiC}$ is due to the differing mechanisms for nanocrystal formation. For the Sirich carbide precursor, nanocrystals precipitate to nucleating sites, due to an excess of $\mathrm{Si}$ in the matrix, with surface energy minimization favoring the formation of spheres. For the near-stoichiometric composition, $\mathrm{SiC}$ nanocrystals formation does not depend on precipitation and hence random shapes occur, dependent more on local concentration variations.

Hence the best data so far for Si nanocrystals in an SiC matrix are obtained for an $\mathrm{Si}_{0.75} \mathrm{C}_{0.25}$ precursor composition. Optical bandgap of $\mathrm{Si}_{0.75} \mathrm{C}_{0.25}$ thin film is in the ranges of $\sim 1.4$ (as-deposited) to $\sim 2.0 \mathrm{eV}$ (annealed at $1100^{\circ} \mathrm{C}$ ). In order to control the size of Si nanocrystals multilayer structures, based on this concentration, have been fabricated and further measurement is underway.

As before, a multilayer approach was used to fabricate $\mathrm{Si}$ QDs in carbide of uniform size. A multilayer with stoichiometric $\mathrm{SiC}$ and silicon-rich $\mathrm{Si}_{1-x} \mathrm{C}_{x}$ precursor layer was fabricated, as shown in Figure 7(a), and annealed at a high temperature to selectively precipitate $\mathrm{Si}$ nanocrystals in a carbide matrix. However, the lattice fringes in HRTEM image correspond to $\beta$-SiC $\{111\}$ crystalline planes (Figure $7(\mathrm{~b})$ ). One possible reason for SiC QDs, instead of Si QDs, is that the $\mathrm{C} / \mathrm{Si}$ ratio in layered structure has an increase, compared to the original design. 


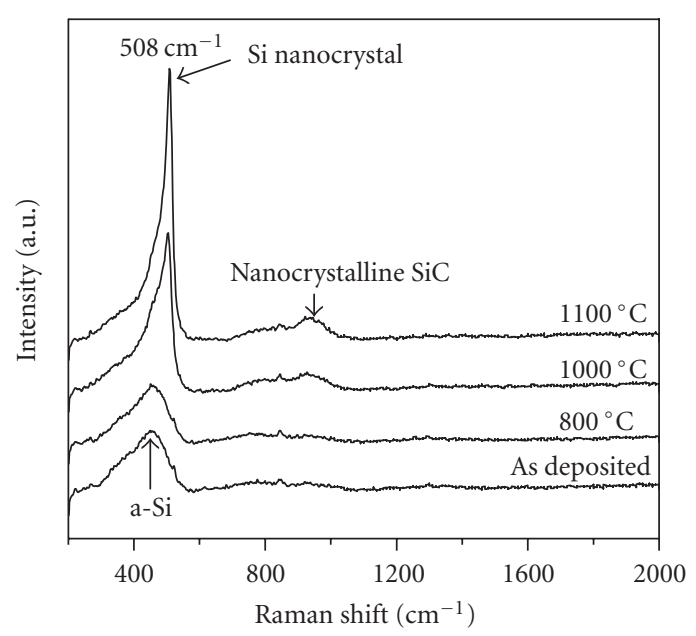

(a)

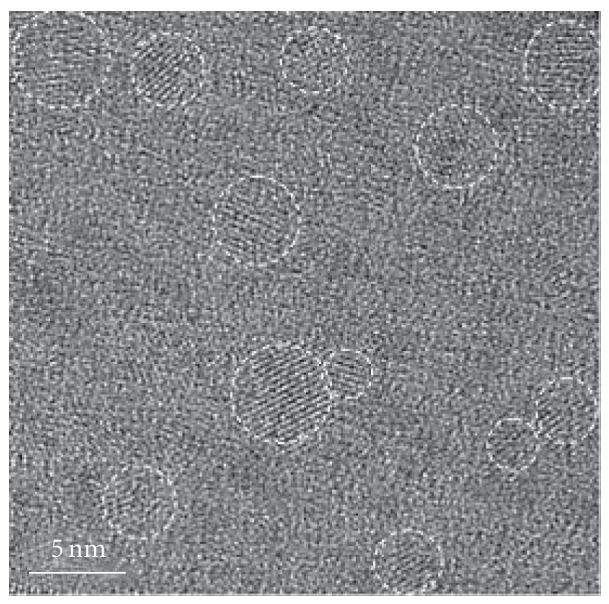

(b)

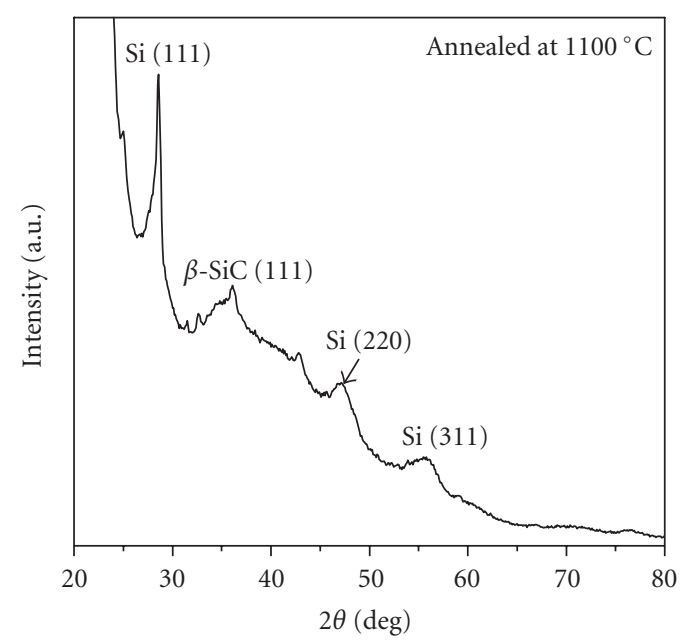

(c)

FIGURE 6: Silicon-rich SiC precursor layer: (a) Raman spectra with different annealing temperature, (b) cross-sectional HRTEM image, and (c) X-ray diffraction pattern.

\subsection{Bandgap engineering of silicon nanostructure}

In indirect bandgap semiconductors, the optical transitions are allowed only if photons are absorbed or emitted to conserve the crystal momentum. The spatial confinement of electrons and holes inside a QD relaxes this k-conservation requirement and creates a quasidirect bandgap [36]. Our measurements of photoluminescence (PL) from Si QDs in silicon oxide confirmed that we get the $1.7 \mathrm{eV}$ bandgap from $2 \mathrm{~nm}$ quantum dots $[5,6,28]$. They also show that there is a large increase in PL intensity as the QD size decreases, which is consistent with the increase in radiative efficiency with the onset of pseudodirect bandgap behavior.

The photoluminescence peaks from Si QDs in nitride are more blue-shifted than that of Si QD in oxide. Figure 8 shows the PL peak energies from Si QD dispersed in oxide [37-39] and nitride $[40,41]$. PL peak energies of Si QDs in oxide are less than $2.0 \mathrm{eV}$, while Si QDs in nitride have peak energies less than $3.0 \mathrm{eV}$. Puzder et al. [42] have explained that the main reason for the PL peak energy reduction in oxide matrix is the distortion of the local $\mathrm{sp}^{3}$ network by double-bonded oxygen. However, Yang et al. [43] claimed that the reason for the stronger blue shift in nitride is better passivation of $\mathrm{Si}$ QDs by nitrogen atoms, eliminating the strain at the $\mathrm{Si} / \mathrm{Si}_{3} \mathrm{~N}_{4}$ interface nearly completely. Our PL results from the Si precipitation are in quite good agreement with the results from other authors [37-43].

Clear evidence of confinement in Si quantum dots in carbide was hard to obtain, probably due to many surface and defect states which dominate the photoluminescence process [34]. An observation of clear quantum confinement in the Si QDs, dispersed in SiC matrix, is also very challenging since usually metastable alloy films relax by diffusion and/or misfit dislocation formation to reduce chemical modulation and strain. It is likely that the mechanism of precipitation of excess $\mathrm{Si}$ atoms to nucleating sites in Si-rich $\mathrm{SiC}$ is a less active process than in nitride or oxide. This would be because the difference in $\mathrm{Si}-\mathrm{Si}$ and $\mathrm{Si}-\mathrm{C}$ lattice spacing is less than in the nitride and oxide. Also because $\mathrm{SiC}$ is an isoelectronic covalently bonded material as is $\mathrm{Si}$; there is a much smaller tendency for segregation of Si than in oxide or nitride matrixes.

\subsection{Mobility-lifetime product}

Photo-generated carriers in an Si quantum dot superlattice need to be collected at the metal contacts and hence require a reasonable mobility. A knowledge of mobility variation for the Si QDs in different matrices, with different barrier thickness and different doping densities in the Si QDs, is important to achieving a working device. Simulations of large bandgap cells using PC1D suggest mobility-lifetime products above $10^{-9} \mathrm{~cm}^{2} / \mathrm{V}$ which are required for good current collection for an indicative top tandem cell design thickness of 100-200 nm (Figure 2). Such a narrow absorber layer is thought reasonable given the improved optical absorption properties of the QD material.

The carrier lifetime of a thin-film material can be characterized by PL decay. Photoluminescence in QD structures involves electron-hole recombination between discrete energy 


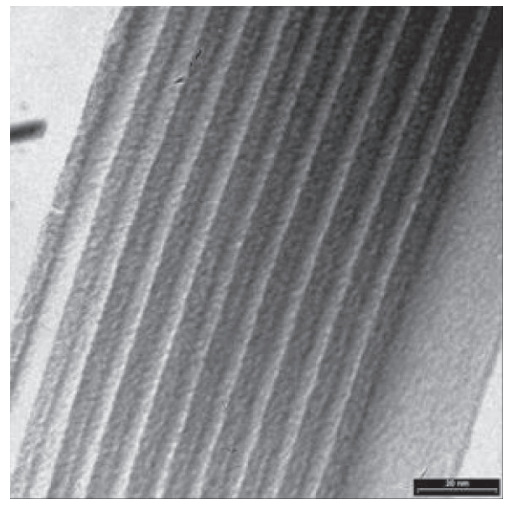

(a)

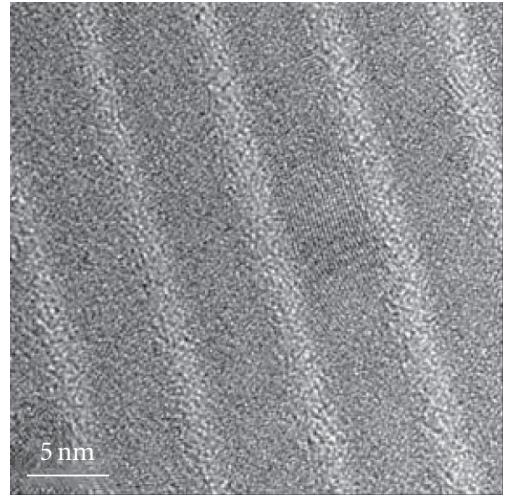

(b)

FIGURE 7: TEM images of SiC/Silicon-rich SiC multilayer (a) deposited and (b) annealed at $1100^{\circ} \mathrm{C}$ for 20 minutes.

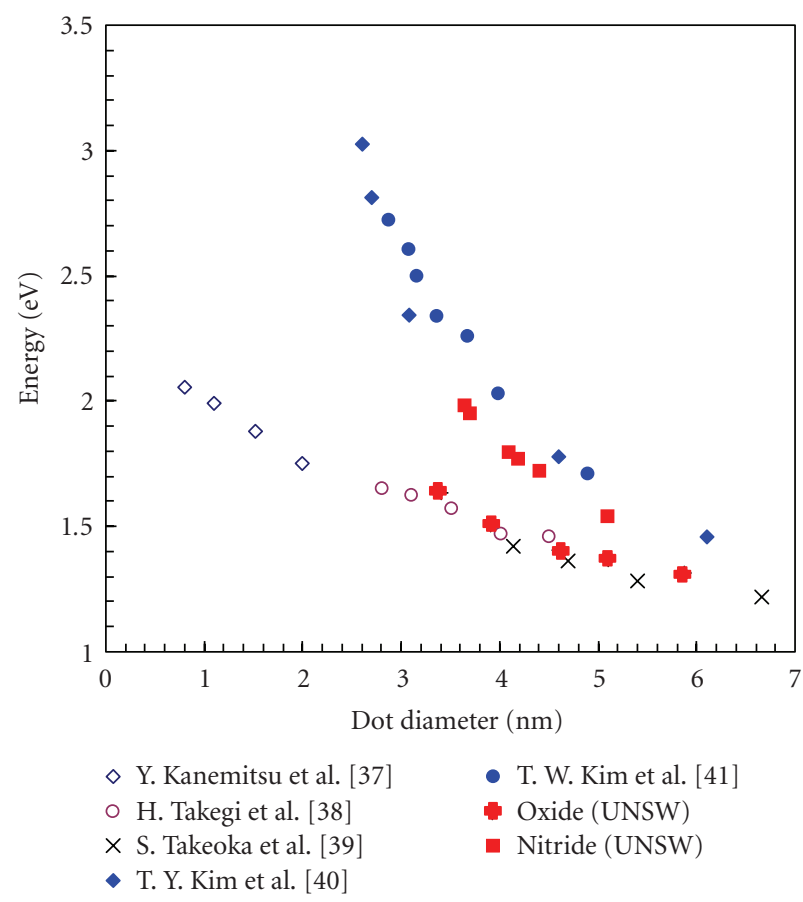

FIGURE 8: Energy gaps of three-dimensionally confined Si nanocrystals in $\mathrm{SiO}_{2}$ and $\mathrm{SiN}_{x}\left(300^{\circ} \mathrm{K}\right)$.

states in the conduction band and the valence band. A PL signal around $750 \mathrm{~nm}$ with a very broadband $(\sim 350 \mathrm{meV})$ is observed for the QD diameter of $3.4 \mathrm{~nm}$ (Figure 9). Despite the broadness of the peaks, there is evidence in Figure 9 that as the excitation intensity is increased the PL intensity of the low energy part of the spectrum (800 and $850 \mathrm{~nm}$ in Figure 9) increases more slowly than that of the high energy part. According to state-filling effect theory, lower energy levels with a low density of states (triplet states) will become saturated as intensity increases, but higher energy levels with a larger DOS (singlet states) will still be available for excitation as high excitation intensities increase [44]. These triplet

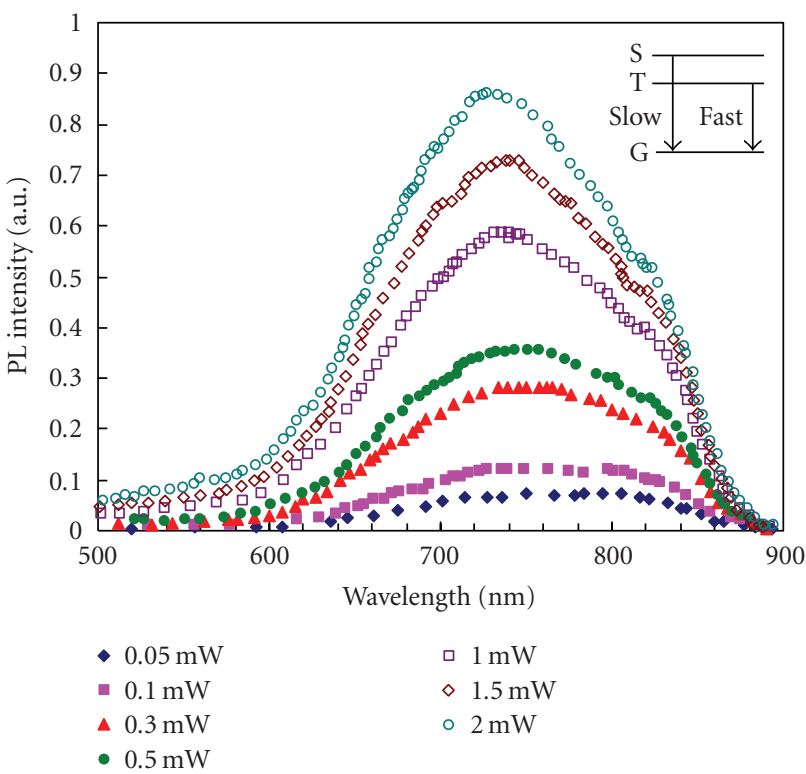

Figure 9: Time-integrated spectrum of Si quantum dot sample measured at different excitation intensities for $3.4 \mathrm{~nm}$ dot size.

TABLe 1: Decay time for different detection wavelengths with $\beta=$ 0.6 for dot diameter of $3.4 \mathrm{~nm}$ and $\beta=0.54$ for dot diameter of $4.2 \mathrm{~nm}$.

\begin{tabular}{l|rrrrrr}
\hline Detection $\lambda(\mathrm{nm})$ & 600 & 650 & 700 & 750 & 800 & 850 \\
$3.4 \mathrm{~nm} \operatorname{dots}(\mu \mathrm{s})$ & 4 & 7 & 12 & 20 & 35 & 60 \\
$4.2 \mathrm{~nm}$ dots $(\mu \mathrm{s})$ & 2 & 4 & 10 & 18 & 20 & 55 \\
\hline
\end{tabular}

and singlet states seem to occur in Si QDs in oxide matrix at about 820 and $740 \mathrm{~nm}$, respectively, as in Figure 9.

Because the PL spectrum of the Si QDs is very broad and the recombination of carriers in different energy levels cannot be clearly resolved, information about the PL lifetime for different levels (with a spectral window of $2 \mathrm{~nm}$ in $50 \mathrm{~nm}$ ) is spread across the spectrum $(600-850 \mathrm{~nm})$. Temporal evolution of the PL can be expressed as a stretched exponential function. This apporach is frequently used to describe 


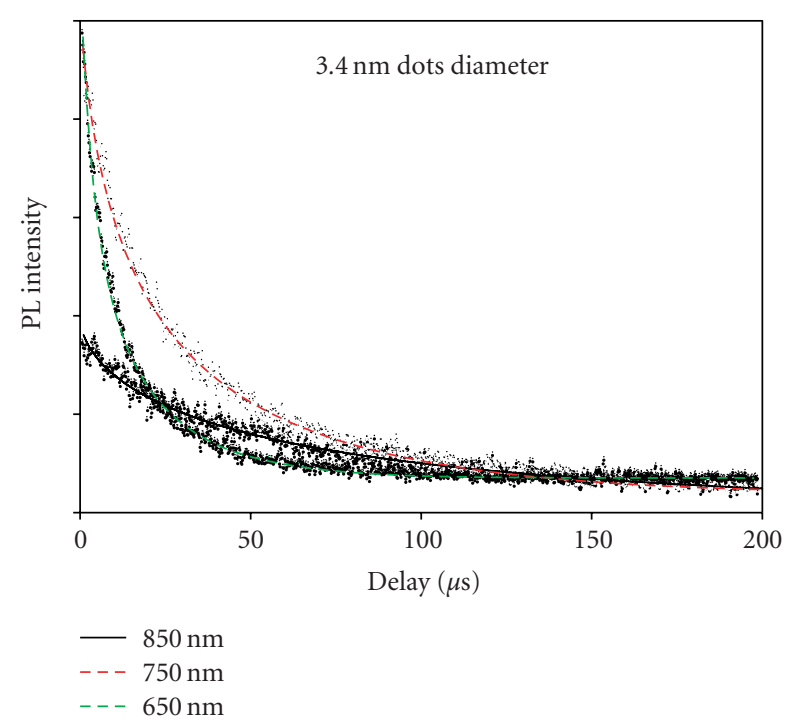

(a)

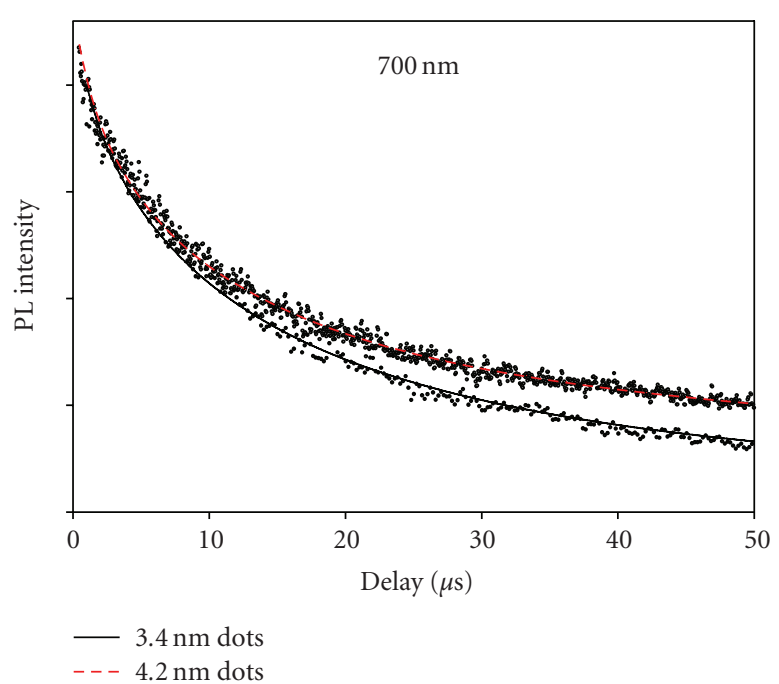

(b)

FIgUre 10: Time-evolution of the PL intensities (a) at detection wavelengths of $650 \mathrm{~nm}, 750 \mathrm{~nm}$, and $850 \mathrm{~nm}$ for $3.4 \mathrm{~nm}$ Si QDs fitted with a stretched exponential function and (b) at a detection wavelength of $700 \mathrm{~nm}$ for $3.4 \mathrm{~nm}$ and $4.2 \mathrm{~nm}$ Si QDs.

dispersive processes in disordered systems, for example, porous silicon, having a distribution of relaxation times, and is given by

$$
I(t)=I_{o} \cdot \exp \left\lfloor-(t / \tau)^{\beta}\right\rfloor,
$$

where $\tau$ is the PL lifetime and $0 \leq \beta \leq 1$ is the dispersion exponent. The PL decay shows that the lifetimes vary from 2 to 60 microseconds for diameter of $3.4 \mathrm{~nm}$ dot with increasing detection wavelength [44]. Figure 10 shows timeevolution of the PL intensities (a) at detection wavelengths of $650 \mathrm{~nm}, 750 \mathrm{~nm}$, and $850 \mathrm{~nm}$ for $3.4 \mathrm{~nm}$ Si QDs fitted with a stretched exponential function and (b) at a detection wavelength of $700 \mathrm{~nm}$ for $3.4 \mathrm{~nm}$ and $4.2 \mathrm{~nm}$ Si QDs, demonstrating that the stretched exponential makes a good fit to the data at both the long and short time scales. Table 1 summarizes the PL decay times from the different detection wavelengths. The dispersion factor is $\beta=0.6$ for sample $3.4 \mathrm{~nm}$ dot and $\beta=0.54$ for $4.2 \mathrm{~nm}$ dot. $\beta$ does not reflect microscopic properties which depend on the size of the QD but rather a macroscopic property of the system associated with the character of the medium [45]; thus the two samples exhibit a difference in the structure of the SRO layer and QDs surface states. The stretched function is related to a distribution of relaxation times or a time-dependent relaxation rate which reflects the interlevel relaxation processes in the QD. In all samples, the lifetime of a high energy level is short. The time decay in nitride matrix is under investigation.

\subsection{Doping and work function control}

The impurities, like phosphorous and boron in the bulk crystalline silicon, increase the conductivity of bulk Si by several orders of magnitude. There are several questions about the impurity doping in a low-dimensional structure [46]. Important questions arise as to whether the dopants will con- tinue to play a role similar to that in bulk semiconductors, or alternative methods of work function control will be required. It is not clear at present whether or not the doping of Si QDs provides the generation of free charge carriers [47]. Also when silicon-rich precursor layers experience phase separation process described in (2), doping impurities may be thermodynamically unfavorable to incorporate into QDs since very small QDs are often regarded as structurally perfect. As a result, in worst case, impurity may not exist inside QDs after high temperature postannealing process.

To study the doping in Si QDs, we choose atoms with a high solid solubility in silicon at the annealing temperature. From this aspect, phosphorus and boron would be the best material for n-type and p-type doping materials, respectively. In our experiments, the phosphorus doping in the Si QD superlattices was achieved using $\mathrm{P}_{2} \mathrm{O}_{5}$ cosputtering during the deposition of silicon-rich oxide ( $\mathrm{Si}$ and $\mathrm{SiO}_{2}$ co-sputtering), which forms $\mathrm{Si}$ QDs upon high temperature postannealing. The $\mathrm{P}$ concentration in the siliconrich oxide was controlled by the deposition rate of three targets and is initially chosen to be very high in order to increase the chances of detection. Phosphorus $2 \mathrm{p}$ X-ray photoelectron spectroscopy (XPS) spectra show that $\mathrm{P}-\mathrm{O}$ bonds (peak around $135 \mathrm{eV}$ ) and $\mathrm{P}-\mathrm{Si}$ bonds and/or free phosphorus (peak around $129 \mathrm{eV}$ ) are observed from highly P-doped silicon-rich oxide (Figure 11 ). $\mathrm{SiO}_{1.41}$ with 0.67 at \% phosphorus shows both $\mathrm{Si}-\mathrm{P}$ and $\mathrm{O}-\mathrm{P}$ bonding, while siliconrich $\mathrm{SiO}_{0.94}$ with 0.27 at \% phosphorus shows only $\mathrm{Si}-\mathrm{P}$ bonding. Control of the $\mathrm{P}$ concentration in this way was high, in the ranges of 0.26 at $\% \sim 3.02$ at \%. The XPS results indicate that the phosphorus in silicon-rich oxide may exist in $\mathrm{Si}-\mathrm{P}$ bonds inside Si QDs. However, it is necessary to carry out more analytical experiments for both n-type and p-type Si QDs in different matrices. 


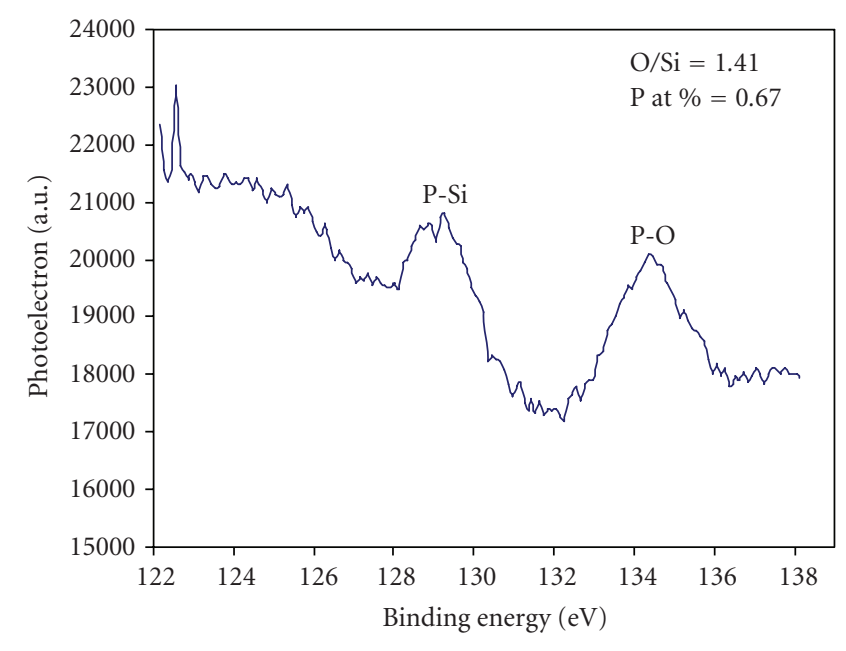

(a)

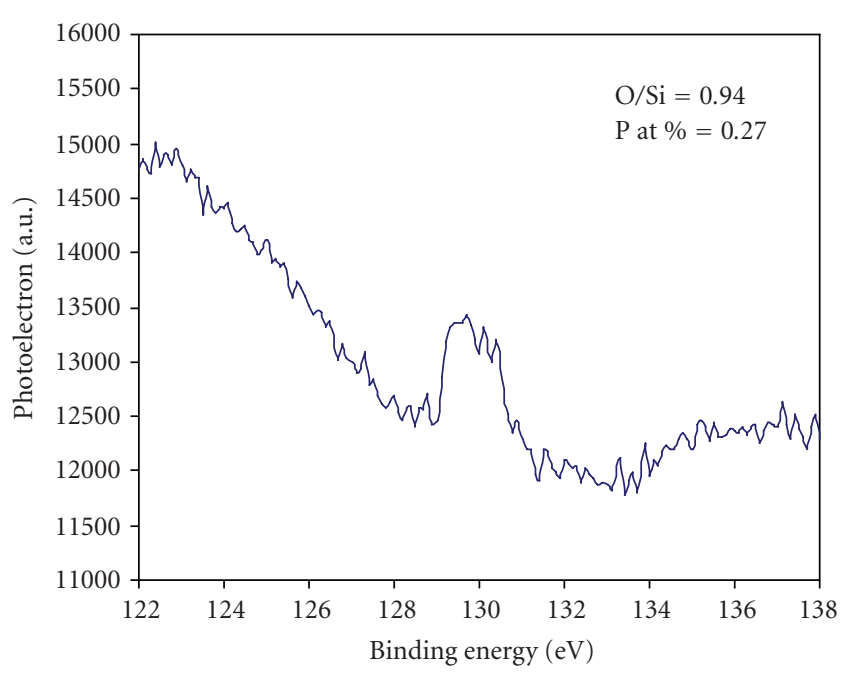

(b)

FIGURE 11: XPS spectra of $\mathrm{P}-\mathrm{Si}$ and $\mathrm{P}-\mathrm{O}$ bonding from (a) $\mathrm{SiO}_{1.41}$ with phosphorus concentration of 0.67 at $\%$ and (b) $\mathrm{SiO}_{0.94}$ with phosphorus concentration of 0.27 at $\%$.

\section{CONCLUSIONS}

Third generation photovoltaic devices aim to tackle the losses associated with the nonabsorption of below bandgap photons and the thermalisation of above bandgap photons to the band edge. To tackle these losses, we are using silicon-based nanostructures as a high bandgap material for the concept of tandem solar cell.

Silicon has a bandgap just slightly larger than the ideal value for the lower cell in a two-cell or even a three-cell tandem stack. An upper material bandgap of $1.7 \sim 1.8 \mathrm{eV}$ for a two-cell tandem solar cell with an Si bottom cell will maximize conversion efficiency. The optimum bandgaps for a three-cell tandem are $1.5 \mathrm{eV}$ and $2.0 \mathrm{eV}$ for middle and uppermost cells, respectively. The current work discusses the engineering of materials with appropriate bandgaps, using $\mathrm{Si}$ QDs dispersed either in silicon oxide, silicon nitride, or silicon carbide.

The formation of Si QDs in oxide and nitride matrices has been demonstrated, with good dot size control and evidence of nanocrystallinity from HRTEM and XRD. Quantum confinement has been demonstrated, using PL for the matrices of oxide and nitride, with PL energy increasing as dot size decreases by the correct relative amounts predicted by confined quantum confinement theory. A transfer of the technology to Si QDs in a silicon carbide matrix has been successfully demonstrated in single layer and multilayer structures, but demonstration of clear quantum confinement in the Si QDs is challenging due to a dominant surface state.

PL decay measurements of Si QDs dispersed in oxide show a slow decay (several tens of microseconds) in the lower part of PL spectrum and fast decay (few microseconds) in the higher part of the PL spectrum. This may be due to singlettriplet splitting in Si QDs dispersed in oxide. There is some initial evidence for n-type doping in Si QDs, which may enable us to make a fully working device.

\section{ACKNOWLEDGMENTS}

This work was supported by the Stanford University Global Climate and Energy Project (GCEP) as well as by the Australian Research Council (ARC) via its Centres of Excellence scheme.

\section{REFERENCES}

[1] M. A. Green, Third Generation Photovoltaics: Advanced Solar Energy Conversion, Springer, Berlin, Germany, 2003.

[2] J. Nelson, The Physics of Solar Cells, Imperial College Press, London, UK, 2003.

[3] W. E. McMahon, S. Kurtz, K. Emery, and M. S. Young, "Criteria for the design of $\mathrm{GaInP} / \mathrm{GaAs} / \mathrm{Ge}$ triple-junction cells to optimize their performance outdoors," in Proceedings of the 29th IEEE Photovoltaic Specialists Conference, pp. 931-934, New Orleans, La, USA, May 2002.

[4] A. V. Shah, J. Bailat, E. Vallat-Sauvain, et al., "Microcrystalline and "micromorph" solar cells and modules: status and potential," in Proceedings of the 31st IEEE Photovoltaic Specialists Conference, pp. 1353-1358, Lake Buena Vista, Fla, USA, January 2005.

[5] M. A. Green, E.-C. Cho, Y. Cho, et al., "All-silicon tandem cells based on "artificial" semiconductor synthesised using silicon quantum dots in a dielectric matrix," in Proceedings of the 20th European Photovoltaic Solar Energy Conference and Exhibition, p. 3, Barcelona, Spain, June 2005.

[6] G. Conibeer, M. A. Green, R. Corkish, et al., "Silicon nanostructures for third generation photovoltaic solar cells," Thin Solid Films, vol. 511-512, pp. 654-662, 2006.

[7] F. Meillaud, A. Shah, C. Droz, E. Vallat-Sauvain, and C. Miazza, "Efficiency limits for single-junction and tandem solar cells," Solar Energy Materials and Solar Cells, vol. 90, no. 1819, pp. 2952-2959, 2006.

[8] E.-C. Cho, M. A. Green, J. Xia, R. Corkish, P. Reece, and M. Gal, "Clear quantum-confined luminescence from crystalline silicon $/ \mathrm{SiO}_{2}$ single quantum wells," Applied Physics Letters, vol. 84, no. 13, pp. 2286-2288, 2004. 
[9] W. van Roosbroeck and W. Shockley, "Photon-radiative recombination of electrons and holes in germanium," Physical Review, vol. 94, no. 6, pp. 1558-1560, 1954.

[10] M. A. Green, G. Conibeer, D. König, et al., "Progress with allsilicon tandem cells based on silicon quantum dots in a dielectric matrix," in Proceedings of the 21th European Photovoltaic Solar Energy Conference, Dresden, Germany, June 2006.

[11] S. Zafar, K. A. Conrad, Q. Liu, et al., "Thickness and effective electron mass measurements for thin silicon dioxide films using tunneling current oscillations," Applied Physics Letters, vol. 67, no. 7, pp. 1031-1033, 1995.

[12] P. C. Arnett and D. J. DiMaria, "Contact currents in silicon nitride," Journal of Applied Physics, vol. 47, no. 5, pp. 20922097, 1976.

[13] C. Persson and U. Lindefelt, "Detailed band structure for 3C-, $2 \mathrm{H}-, 4 \mathrm{H}-, 6 \mathrm{H}-\mathrm{SiC}$, and $\mathrm{Si}$ around the fundamental band gap," Physical Review B, vol. 54, no. 15, pp. 10257-10260, 1996.

[14] C.-W. Jiang and M. A. Green, "Silicon quantum dot superlattices: modeling of energy bands, densities of states, and mobilities for silicon tandem solar cell applications," Journal of Applied Physics, vol. 99, no. 11, Article ID 114902, 7 pages, 2006.

[15] L. L. Chang, L. Esaki, W. E. Howard, and R. Ludeke, "The growth of a GaAs-GaAlAs superlattice," Journal of Vacuum Science and Technology, vol. 10, no. 1, pp. 11-16, 1973.

[16] B. Abeles and T. Tiedje, "Amorphous semiconductor superlattices," Physical Review Letters, vol. 51, no. 21, pp. 2003-2006, 1983.

[17] Z. H. Lu, D. J. Lockwood, and J.-M. Baribeau, "Quantum confinement and light emission in $\mathrm{SiO}_{2} / \mathrm{Si}$ superlattices," Nature, vol. 378, no. 6553, pp. 258-260, 1995.

[18] H. Morisaki, H. Hashimoto, F. W. Ping, H. Nozawa, and H. Ono, "Strong blue light emission from an oxygen-containing Si fine structure," Journal of Applied Physics, vol. 74, no. 4, pp. 2977-2979, 1993.

[19] K. A. Littau, P. J. Szajowski, A. J. Muller, A. R. Kortan, and L. E. Brus, "A luminescent silicon nanocrystal colloid via a hightemperature aerosol reaction," Journal of Physical Chemistry, vol. 97, no. 6, pp. 1224-1230, 1993.

[20] Y. Maeda, N. Tsukamoto, Y. Yazawa, Y. Kanemitsu, and Y. Masumoto, "Visible photoluminescence of Ge microcrystals embedded in $\mathrm{SiO}_{2}$ glassy matrices," Applied Physics Letters, vol. 59, no. 24, pp. 3168-3170, 1991.

[21] M. Zacharias, J. Heitmann, R. Scholz, U. Kahler, M. Schmidt, and J. Bläsing, "Size-controlled highly luminescent silicon nanocrystals: a $\mathrm{SiO} / \mathrm{SiO}_{2}$ superlattice approach," Applied Physics Letters, vol. 80, no. 4, pp. 661-663, 2002.

[22] L. Tsybeskov, K. D. Hirschman, S. P. Duttagupta, et al., "Fabrication of nanocrystalline silicon superlattices by controlled thermal recrystallization,” Physica Status Solidi A, vol. 165, no. 1, pp. 69-77, 1998.

[23] T. Shimizu-Iwayama, S. Nakao, and K. Saitoh, "Visible photoluminescence in $\mathrm{Si}^{+}$-implanted thermal oxide films on crystalline Si," Applied Physics Letters, vol. 65, no. 14, pp. 18141816, 1994.

[24] L. Patrone, D. Nelson, V. Safarov, M. Sentis, and W. Marine, "Size dependent photoluminescence from Si nanoclusters produced by laser ablation," Journal of Luminescence, vol. 80, no. 1-4, pp. 217-221, 1998.

[25] R. A. Bley and S. M. Kauzlarich, "A low-temperature solution phase route for the synthesis of silicon nanoclusters," Journal of the American Chemical Society, vol. 118, no. 49, pp. 1246112462, 1996.

[26] C. Lam, Y. F. Zhang, Y. H. Tang, C. S. Lee, I. Bello, and S. T. Lee, "Large-scale synthesis of ultrafine Si nanoparticles by ball milling," Journal of Crystal Growth, vol. 220, no. 4, pp. 466470, 2000.

[27] O. Akcakir, J. Therrien, G. Belomoin, et al., "Detection of luminescent single ultrasmall silicon nanoparticles using fluctuation correlation spectroscopy," Applied Physics Letters, vol. 76, no. 14, pp. 1857-1859, 2000.

[28] E.-C. Cho, Y.-H. Cho, T. Trupke, R. Corkish, G. Conibeer, and M. A. Green, "Silicon nanostructures for all-silicon tandem solar cells," in Proceedings of the 19th European Photovoltaic Solar Energy Conference and Exhibition, p. 235, Paris, France, June 2004.

[29] N.-M. Park, T.-S. Kim, and S.-J. Park, "Band gap engineering of amorphous silicon quantum dots for light-emitting diodes," Applied Physics Letters, vol. 78, no. 17, pp. 2575-2577, 2001.

[30] S. Lombardo and S. U. Campisano, "Electrical and optical properties of semi-insulating polycrystalline silicon thin films: the role of microstructure and doping," Materials Science and Engineering, vol. 17, no. 8, pp. 281-336, 1996.

[31] Y. Cho, E.-C. Cho, Y. Huang, T. Trupke, G. Conibeer, and M. A. Green, "Silicon quantum dots in SiNx matrix for third generation photovoltaics," in Proceedings of the 20th European Photovoltaic Solar Energy Conference and Exhibition, p. 47, Barcelona, Spain, June 2005.

[32] Y. Kurokawa, S. Miyajima, A. Yamada, and M. Konagai, "Preparation of nanocrystalline silicon in amorphous silicon carbide matrix," Japanese Journal of Applied Physics, vol. 45, no. 40, pp. L1064-L1066, 2006.

[33] D. Song, E.-C. Cho, Y.-H. Cho, et al., "Evolution of Si (and $\mathrm{SiC}$ ) nanocrystal precipitation in SiC matrix," (In press)Thin Solid Films.

[34] J. Y. Fan, X. L. Wu, and P. K. Chu, "Low-dimensional SiC nanostructures: fabrication, luminescence, and electrical properties," Progress in Materials Science, vol. 51, no. 8, pp. 983-1031, 2006.

[35] J. Zi, H. Büscher, C. Falter, W. Ludwig, K. Zhang, and X. Xie, "Raman shifts in Si nanocrystals," Applied Physics Letters, vol. 69, no. 2, pp. 200-202, 1996.

[36] D. Kovalev, H. Heckler, M. Ben-Chorin, G. Polisski, M. Schwartzkopff, and F. Koch, "Breakdown of the $k$ conservation rule in Si nanocrystals," Physical Review Letters, vol. 81, no. 13, pp. 2803-2806, 1998.

[37] Y. Kanemitsu, "Light-emitting silicon materials," Journal of Luminescence, vol. 70, no. 1-6, pp. 333-342, 1996.

[38] H. Takagi, H. Ogawa, Y. Yamazaki, A. Ishizaki, and T. Nakagiri, "Quantum size effects on photoluminescence in ultrafine Si particles," Applied Physics Letters, vol. 56, no. 24, pp. 23792380, 1990.

[39] S. Takeoka, M. Fujii, and S. Hayashi, "Size-dependent photoluminescence from surface-oxidized Si nanocrystals in a weak confinement regime," Physical Review B, vol. 62, no. 24, pp. 16820-16825, 2000.

[40] T.-Y. Kim, N.-M. Park, K.-H. Kim, et al., "Quantum confinement effect of silicon nanocrystals in situ grown in silicon nitride films," Applied Physics Letters, vol. 85, no. 22, pp. 53555357, 2004.

[41] T.-W. Kim, C.-H. Cho, B.-H. Kim, and S.-J. Park, "Quantum confinement effect in crystalline silicon quantum dots in silicon nitride grown using $\mathrm{SiH}_{4}$ and $\mathrm{NH}_{3}$," Applied Physics Letters, vol. 88, no. 12, Article ID 123102, 3 pages, 2006.

[42] A. Puzder, A. J. Williamson, J. C. Grossman, and G. Galli, "Surface control of optical properties in silicon nanoclusters," Journal of Chemical Physics, vol. 117, no. 14, pp. 6721-6729, 2002.

[43] M.-S. Yang, K.-S. Cho, J.-H. Jhe, et al., "Effect of nitride passivation on the visible photoluminescence from 
Si-nanocrystals," Applied Physics Letters, vol. 85, no. 16, pp. 3408-3410, 2004.

[44] L. Van Dao, X. Wen, M. T. T. Do, et al., "Time-resolved and time-integrated photoluminescence analysis of state filling and quantum confinement of silicon quantum dots," Journal of Applied Physics, vol. 97, no. 1, Article ID 013501, 5 pages, 2005.

[45] M. Dovrat, Y. Goshen, J. Jedrzejewski, I. Balberg, and A. Sa'ar, "Radiative versus nonradiative decay processes in silicon nanocrystals probed by time-resolved photoluminescence spectroscopy," Physical Review B, vol. 69, no. 15, Article ID 155311, 8 pages, 2004.

[46] S. Ossicini, F. Iori, E. Degoli, et al., "Understanding doping in silicon nanostructures," IEEE Journal on Selected Topics in Quantum Electronics, vol. 12, no. 6, pp. 1585-1590, 2006.

[47] G. Polisski, D. Kovalev, G. Dollinger, T. Sulima, and F. Koch, "Boron in mesoporous $\mathrm{Si}$ - where have all the carriers gone?" Physica B, vol. 273-274, pp. 951-954, 1999. 

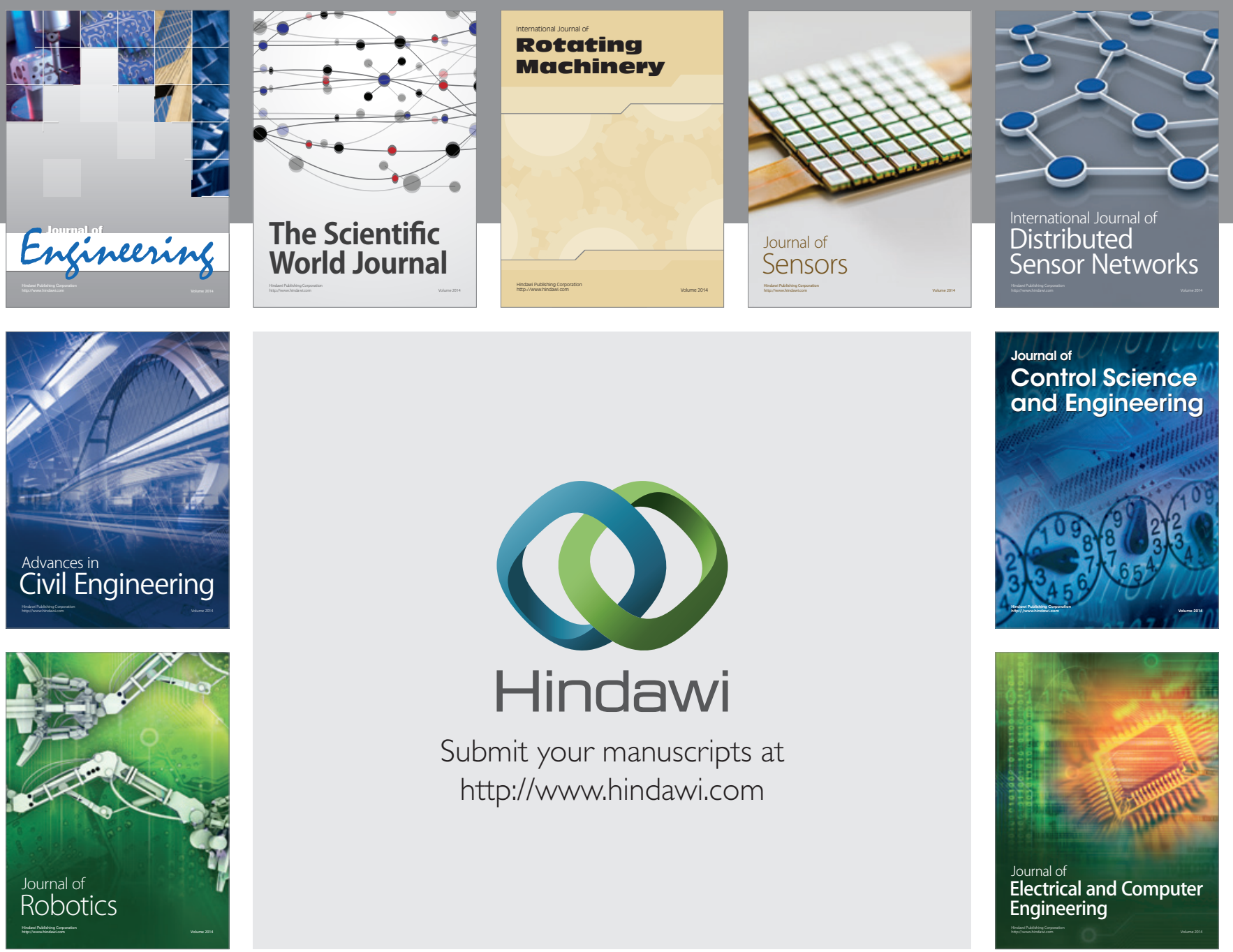

Submit your manuscripts at

http://www.hindawi.com
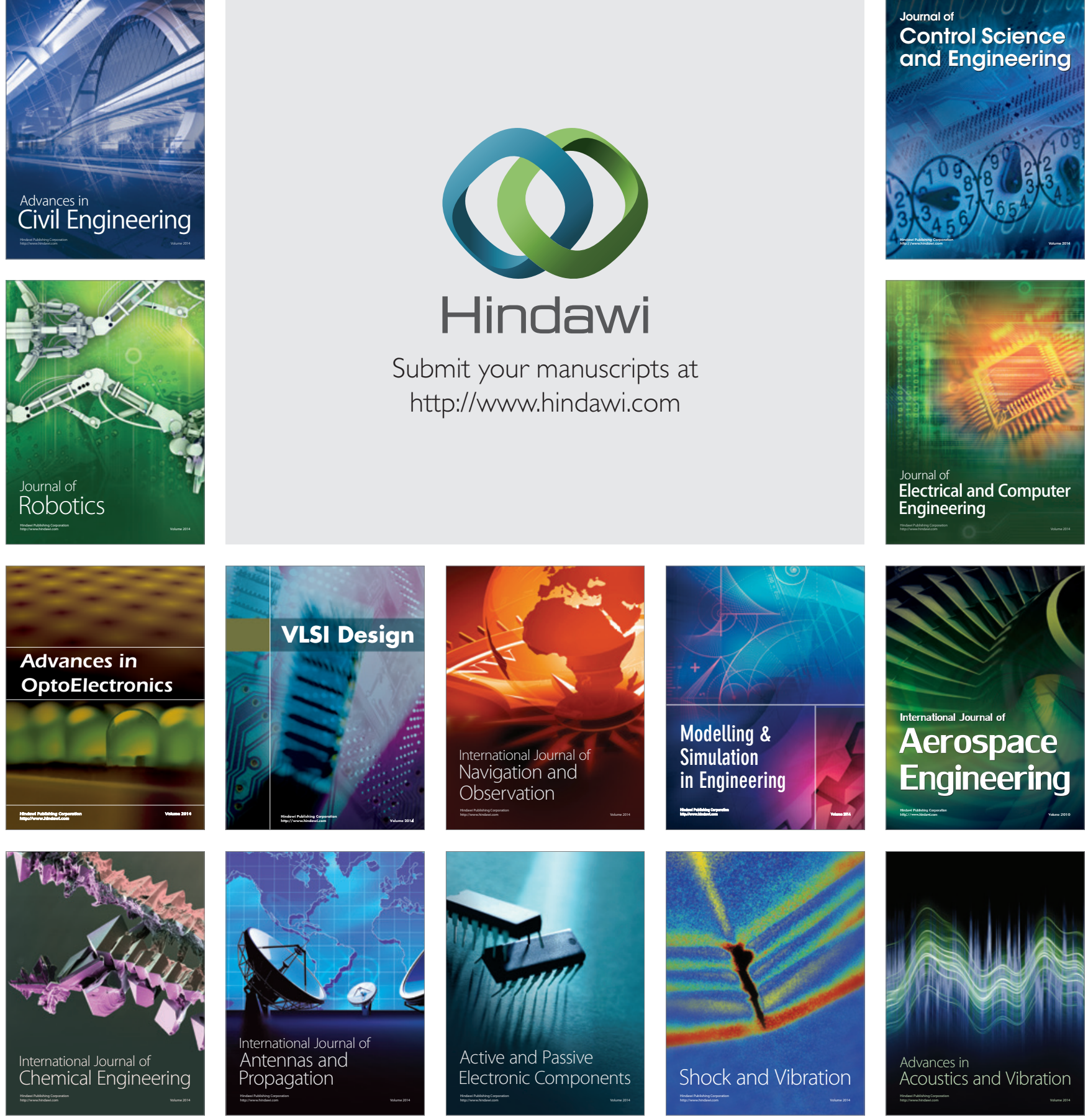